\title{
Biodiversity and genomics of diatoms
}

\author{
D. Romanova*, E. Nevrova \\ The A.O. Kovalevsky Institute of Marine Biological Research of RAS, Sevastopol, Russia \\ *e-mail:driaromanova@yandex.ru
}

Key words: diatoms, biodiversity, genomics

Motivation and Aim: Diatoms are single-cell photosynthetic algae that fix up to $20 \%$ of total marine primary productivity [1]. Biodiversity of diatoms is huge: $a .12000$ diatom species have already been described, and $a .100000$ are assumed to exist [2]. In this regard, joint analysis on the species richness assessment and genomes survey of Bacillariophyta are the crucial both for development of the measures to maintain the sustainable functioning of marine ecosystem chains and conservation of the gene pool. Based on the published sources and own surveys, the current taxonomic richness of Black Sea benthic diatoms was evaluated. Updated diatom inventory holds 1094 species and intraspecific taxa, pooled in 953 species, 149 genera, 61 families, 32 order and 3 classes Bacillariophyta [3]. At present, genomes of 8 diatom species have been obtained only [4-6]. The mainstream of diatom research is elicitation of genes responsible for the silicon transport during the valves morphogenesis, the uptake of high-affinity iron, biosynthetic enzymes, a complete urea cycle. An explanation of these mechanisms will help to understand the wide prevalence of diatoms, which able to survive even in soils, ice and hot springs. Another important aim is the study of diatom genetic regulatory elements that determine gene expression and the light response regulation [7]. According to some data, there is a mechanism for switching from phototrophic to heterotrophic feeding under limited light regime.

Conclusion: Combined taxonomical evaluation of diatom diversity and its genomes should be employed for necessity of environmental security measures and conservation of marine flora biodiversity at the modern transformation and anthropogenic development of the Black Sea and World Ocean shores. The obtained in future research results will allow to consider the diatom evolution, ecology and metabolism processes within the framework of the biodiversity concept.

Acknowledgements: Supported by the Ministry of Education and Science of the Russian Federation grant No. 14.W03.31.0015.

\section{References}

1. The Diatom World. Seckbach J., Kociolek J.P. (eds) (2011) Dordrecht, Heidelberg, London, New-York: Springer. $533 \mathrm{p}$.

2. Mann D.G., Vanormelingen P. (2013) An inordinate fondness? The number, distributions and origins of diatom species. Journal Eukaryotic Microbiology. 60:414-420.

3. Nevrova E.L. (2015) Benthic Diatoms (Bacillariophyta) in the Black Sea: diversity and structure of taxocenes of varios biotopes : Dr. Sci. dissertation, Moscow. $442 \mathrm{p}$.

4. Armbrust E.V. et al. (2004) The Genome of the Diatom Thalassiosira pseudonana: Ecology, Evolution, and Metabolism. Science. 306(5693):79-86.

5. Bowler C. et al. (2004) The Phaeodactylum genome reveals the evolutionary history of diatom genomes. Nature. 456:239-244.

6. Tang X., Bi G. (2016) Complete mitochondrial genome of Fistulifera solaris (Bacillariophycidae). Mitochondrial DNA A DNA Mapp Seq Anal. 27(6):4405-4406.

7. Lepetit B. et al. (2017) The diatom Phaeodactylum tricornutum adjusts NPQ capacity in response to dynamic light via fine-tuned Lhcx and xanthophyll cycle pigment synthesis. New Phytologist. 214(1): 1469-8137. 